\title{
The Cultivation Model of Students' Personalized Innovative and Entrepreneurial Ability in Applied Colleges and Universities
}

\author{
Shunqiang Gong \\ Yunnan University of Bussiness Management, Kunming City, Yunnan \\ Province, 650106, China
}

\begin{abstract}
Personalized education is the fundamental way to cultivate college students' innovative and entrepreneurial ability and it meets the urgent need for college students' development. Exploring the basic connotation of personalized education and its relationship with the cultivation of undergraduates' innovative and entrepreneurial ability is conducive to optimizing the environment and atmosphere of personalized education and cultivating students' innovative and entrepreneurial ability. Based on the author's teaching and practical experience, this paper firstly analyzed the connotation and characteristics of personalized education in Applied colleges and universities. Then, the article discussed the status quo and problems in innovation and entrepreneurship education in Applied colleges and universities in China. Finally, the author proposed the construction strategies of the cultivation model of personalized innovative and entrepreneurial talents in China.

Keywords: Applied colleges and universities; College students; Personalization; Innovative and entrepreneurial ability; Cultivation Model
\end{abstract}

\section{Introduction}

The 18th National Congress of the Communist Party of China (CPC) proposed the goal to improve independent innovation capability and bring China into the ranks of innovative countries by 2020. Building innovative country depends largely on the scale and quality of innovative and entrepreneurial talents, and 
innovation and entrepreneurship training mainly relays on innovation and entrepreneurship education in colleges and universities. National Outline for Medium and Long-term Education Reform and Development clearly pointed out to firmly establish the central position of talent cultivation in colleges and universities, and strive to cultivate high-quality professionals and top-notch innovative talents with faith, perseverance, good moral character, rich knowledge and excellent skills[1]. It is obvious that the innovation and entrepreneurship education of college students is the trend of higher education. Therefore, the innovation and entrepreneurship education in colleges and universities must establish the idea of personalized innovative and entrepreneurial talent cultivation and construct a diversified cultivation model of innovative and entrepreneurial talents. Besides, the innovation and entrepreneurship education should set up a personalized innovation and entrepreneurship education system, improve personalized innovation and entrepreneurship teaching evaluation system and take security measures of personalized innovative and entrepreneurial personnel cultivation.

\section{The Connotation and Characteristics of Personalized Education in Applied Colleges and universities}

The "personality" in personalized education has not yet been defined uniformly. The personalization of education mainly refers to the unique educational means which are conducive to the individual growth. It is based on individual innate character and the influence of education and externalization. Personalized education chooses the unique method that fits the individual to explore individual potential and promote individual free development. Personalized education is different from individual education, one-on-one education or special education, which emphasizes the respect for the individual's personality and potential. It is the process to promote the transformation from educatee's actual personality to ideal personality. Personalized education meets the requirement of time development and the development of higher vocational colleges. Personalized education should be based on two prerequisites: first, find and respect students' personality; second, provide material conditions which are conducive to the improvement of students' individuality. The ultimate goal of personalized education is to cultivate people with personality[2]. The characteristics of personalized education are mainly reflected in the following three aspects: the first is the people-oriented educational thinking. The focus of personalized education is students, and schools and teachers should establish the concept of serving the students, respect their personality and strive for different education and teaching methods. The second is harmonious education. Schools should combine students' comprehensive development and personality development, integrate social development and personal development, and connect personality nature and social unity. The third is to highlight self-education. The development of personality can only be done by oneself and teachers should help students to 
cultivate interest and strengthen self-confidence by virtue of scenario hypothesis, psychological suggestion and self-motivation, so that students can achieve selfgrowth and self-transcendence .

\section{The Status Quo and Problems in Innovation and Entrepreneurship Education in Applied Colleges and Universities in China}

\subsection{The concept of innovation and entrepreneurship education is backward}

Influenced by the traditional education concept, the school education has paid too much attention to imparting knowledge in the classroom and ignores the internship and practical training, which leads to that students do not have a deeper understanding of innovation and entrepreneurship and they can not treat and actively accept innovation and entrepreneurship education as participants. At the same time, there exists certain deviation in the teaching objectives of innovation and entrepreneurship education, which results in the vague training program. Some teachers even believe that only students with poor subject-specific achievement and weak competitiveness in the job market need to start up a business[3]. As educational main bodies, this kind of understanding of the innovation and entrepreneurship education has great negative impact on the realization of educational goals.

\subsection{The curriculum of innovation and entrepreneurship education is imperfect}

The teaching and research of innovation and entrepreneurship is in the initial stage in China. The supporting resources of the entrepreneurship curriculum are not complete and the theoretical content lacks completeness and maturity, which is basically a simple patchwork of the original resources. Besides, there is no perfect logic system in the curriculum. As an independent discipline, the entrepreneurship course lacks rigorously scientific and systematic analysis. The teaching model is not coherent and most of the classes are in the form of lectures. There is no systematic curriculum to train students' innovative thinking and skills, which results in that students poorly understand the innovation and entrepreneurship and they lack enthusiasm and initiative to the courses.

\subsection{The theoretical study of innovation and entrepreneurship education is not systematic}

The teaching of innovation and entrepreneurship education lacks guidance of systematic entrepreneurial theory. Most teachers do not have industry experience and lack entrepreneurial experience, so that they can not really bear their responsibility to impart knowledge, instruct students and answer questions. Moreover, the entrepreneurship education just repeats what the book says and this 
can not fully and systematically guide students' specific innovative and entrepreneurial practice. In addition, it can not meet students' needs of innovation and entrepreneurship. Consequently, students lose their interest in innovation and entrepreneurship education. In the final analysis, the basic reason is that innovation and entrepreneurship education does not form an effective education system.

\subsection{The capital investment of innovation and entrepreneurship education is less}

At present, the innovation and entrepreneurship education in most colleges and universities is still limited to various innovation and entrepreneurship competitions, most of which underline the theory and become a mere formality. Competitions rarely enable students to enhance their comprehensive qualities and skills that meet the need of entrepreneurship. For students' real business plans and entrepreneurship, schools can not provide the appropriate financial support to encourage them to put into practice of their business plans, which stifles their passion to start a business[4].

\section{The Cultivation Model of Students' Personalized Innovative and Entrepreneurial Ability in Colleges in China}

\subsection{To establish a cultivation concept of personalized innovative and entrepreneurial talents}

Innovation and entrepreneurship education is a new model of talent cultivation, which should take the development of students' individuality and potential as the basis to cultivate students' innovative consciousness, innovative thinking, entrepreneurial spirit and entrepreneurial ability. In National Outline for Medium and Long-term Education Reform and Development promulgated and implemented in China, the party and the state take the talent cultivation model innovation and students' personality development as the breakthrough to deepen the reform of education system in the new period. Therefore, colleges and universities should break the shackles of the traditional concept of running a school, and scientifically grasp the intrinsic relationship between innovation and entrepreneurship education, and academic education, professional education and quality education. Besides, colleges innovation and entrepreneurship education should take personnel training model reform and education reform as important things and adhere to the reform throughout in the whole process of personnel training. Entrepreneurship education must be closely integrated with innovative training to cultivate entrepreneurs with entrepreneurial spirit and ability[5]. With the use of Multiple Intelligence Theory proposed by Prof. Gardner, colleges should provide students with a personalized learning environment to develop their intellectual ability, independent thinking, cooperation awareness, selfcognition and social skills, which will mobilize and develop their potential. 


\subsection{To improve supporting measures of personalized innovative and entrepreneurial talent cultivation}

The practice of personalized education is not only a change of traditional educational ideas, but also a useful exploration of the existing educational system and mechanism, which needs supporting measures to ensure its implementation. First of all, colleges should establish a sound innovation and entrepreneurship supporting and incentive system to provide policies for cultivating innovative and entrepreneurial talents. Colleges and universities should formulate relevant systems according to the operation of the project, such as the implementation plan of innovation and entrepreneurship education in colleges, the implementation plan of personalized education for college students and the management approach of innovation and entrepreneurship fund. Schools should set up corresponding credits in personality development and specialty training, and stipulate implementation measures and assessment means for students and teachers, so as to provide a basis for carrying out personalized innovation and entrepreneurship education in the current teaching system smoothly. Second, universities must strengthen the construction of teaching staff with innovative quality to provide teachers for training innovative and entrepreneurial talents[6].

\subsection{To establish a system of personalized innovation and entrepreneurship education}

First, colleges should set up professional development courses and build a skill training platform. With the help of the combination of classroom teaching and project skill training in the studio, students can receive specialized comprehensive project training, which integrates teaching, learning and doing. This model is task-driven and project-oriented, so that students can directly participate in market practice activities to exercise their technical skills. This will help achieve the goal of simultaneous cultivation of professional skills and qualities. Second, universities should improve the personnel training program and establish a professional knowledge development platform. To promote personalized education, schools must handle the relationship between professional adjustment and relative stability well, pay attention to professional characteristics and its development prospect, and strengthen the connotation construction. By virtue of integration, penetration and intersection, colleges should upgrade and improve traditional majors to better meet the needs of modern economy and society[7]. Third, universities should carry out innovation and entrepreneurship practice and set up an innovative practice platform. College students' innovation practice bases should rely on university science parks, talent training model innovative practice bases and innovation and entrepreneurship colleges. Besides, schools may provide students with scientific and technical training programs, campaign money, necessary sites and equipment in the form of project approval to subsidize undergraduate students to carry out research and innovative entrepreneurial experiments. 


\subsection{To optimize the teaching evaluation system of personalized innovation and entrepreneurship}

Schools should establish and optimize diversified evaluation systems which aim at promoting innovation and entrepreneurship, introduce assessment methods besides the examination, and strive to carry out the all-round scientific and rational evaluation of the innovative and entrepreneurial talent cultivation in the whole process. In the evaluation content, universities is supposed to grasp the key points of the course quality, classroom teaching and practice teaching of innovation and entrepreneurship to make the evaluation of the content scientific and accurate; in the evaluation bodies, schools, employers, students and family should participate in the evaluation to make the evaluation of innovation and entrepreneurship universal; evaluation index should not only emphasize standardization, appropriateness and uniformity, but also be personalized based on personnel cultivation orientation of colleges and universities; in the evaluation methods and means, schools should pay attention to monitoring the process and integrating examinations, discipline competitions, innovation and entrepreneurship training and project researches. Universities may set corresponding credits and credits can be replaced and recognized mutually; the evaluation results should not be limited to the mastery of knowledge and schools should pay attention to evaluating the overall effect of innovation and entrepreneurship education.

\section{Conclusion}

With the rapid development of modern society, the education reform of Applied colleges and universities in China has been constantly advancing and the social demand for innovation becomes urgent increasingly. Therefore, in the new era, innovation and entrepreneurship education in colleges and universities should adhere to the personalized principle and combine course reform with corresponding innovation and entrepreneurship competitions to create a new innovation and entrepreneurship campus culture in practice. This will contribute to constructing a scientific, rigorous and effective innovation and entrepreneurship personnel cultivation system, so as to cultivate students' innovative consciousness and practical ability and train innovative and entrepreneurial talents who adapt to the New Normal.

\section{References}

[1] Jiang Hui, Yin Huiguang and Xu Xiaochang. A Research on the Cultivation Model of Personalized Innovative and Entrepreneurial Talents in Colleges and Universities. Journal of National Academy of Education Administration, 03, pp.27-31, 2015. 
[2] Zhu Xia, Pan Chunyong. A Study on the Cultivation Model of Personalized Innovative and Entrepreneurial Ability in Higher Vocational Colleges. Journal of Contemporary Educational Practice and Teaching Research, 10, pp.178 + 177, 2015.

[3] Li Mingtang, Li Cuilan and Liu Jinhua. An Analysis of the Cultivation Model of Personalized Innovative and Entrepreneurial Talents in Colleges and Universities. Modern Communication, 14, pp.231-232, 2016.

[4] Liang Zhenzhen. A Research on the Cultivation Model of Personalized Innovative and Entrepreneurial Talents in Agricultural Colleges and Universities. Agriculture and Technology, 16, pp.176, 2016.

[5] Liu Dan. A Research on the Cultivation Model of Innovative and Entrepreneurial Talents in Colleges and Universities from the Perspective of Personalized Education. Journal of Liaoning Higher Vocational Schools, 08, pp.82-85, 2016.

[6] Zeng Lin. A Research on the Cultivation Model of Personalized Innovative and Entrepreneurial Talents in Colleges and Universities. Cuide to Business, 19, pp.123, 2016.

[7] Zhao Lei. A Research on the Cultivation of Innovative and Entrepreneurial Talents in Colleges and Universities from the Perspective of Personalized Education. Journal of Huaihai Institute of Technology (Humanities and Social Sciences Edition) ,23, pp.23-25, 2013. 